International Journal of Current Advanced Research

ISSN: O: 2319-6475, ISSN: P: 2319 - 6505, Impact Factor: SJIF: 5.995

Available Online at www.journalijcar.org

Volume 6; Issue 5; May 2017; Page No. 3584-3588

DOI: http://dx.doi.org/10.24327/ijcar.2017.3588.0321

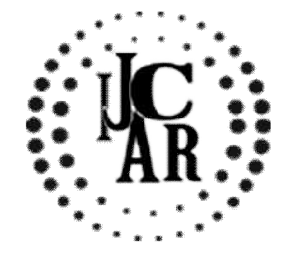

Research Article

\title{
POORLY CONTROLLED DIABETES MELLITUS TYPE 2 IS ASSOCIATED WITH INCREASED MMP-9 LEVELS AND OCCURANCE OF MYOCARDIAL INFARCTION-A PILOT STUDY
}

\section{Veenu Rajdan, Ritu Singh and Sanjay Tyagi}

Department of Biochemistry, Lady Hardinge Medical College, New Delhi, India, G.B.Pant Hospital, New Delhi, India

A R T I C L E I I N F O

\section{Article History:}

Received $5^{\text {th }}$ February, 2017

Received in revised form $16^{\text {th }}$ March, 2017

Accepted $2^{\text {nd }}$ April, 2017

Published online $28^{\text {th }}$ May, 2017

Key words:

Acute myocardial infarction, MMP-9, Diabetes Mellitus type 2

\begin{abstract}
A B S T R A C T
Background: Acute coronary events are seen to be more in Diabetes mellitus (DM) type 2 patients and the etiopathogenesis of this increased atherothrombogenesis is under research.Advanced glycation end products (AGEs) hallmark of DM may increase matrix metalloproteinase which are involved with instability of atherosclerotic plaque.

Aims and Objectives: To evaluate levels of MMP-9 in Acute myocardial infarction (AMI) patients without DM and in (AMI) patients with DM and volunteers with DM and volunteers without DM, and to correlate it with occurance AMI.

Method and Results: Diagnosed patients of AMI without DM ( $n=30)$ and patients of AMI with DM (of atleast 10 years of duration) $(n=30)$ were enrolled from cardiology department, G. B. Pant Hospital, New Delhi as cases, with age and sex matched controls without DM $(n=30)$ and with DM $(n=30)$ after informed consent. $2 \mathrm{ml}$ blood was collected in plain vial for routine biochemical investigations by automated methodologies and plasma MMP-9 levels was estimated using RayBio Human MMP-9 ELISA Kit.We found MMP-9 levels in patients having AMI without DM ( $22.2 \pm 1.2 \mathrm{ng} / \mathrm{ml}$ )was significantly more (pvalue $<0.001)$ than in healthy volunteers without $\mathrm{DM}(21.5 \pm 1.2 \mathrm{ng} / \mathrm{ml})$.We also found MMP-9 levels in patients having AMI with DM $(24.1 \pm 1.1 \mathrm{ng} / \mathrm{ml})$ was significantly more (p-value $<0.001)$ than in healthy volunteers with DM $(22.4 \pm 1.5 \mathrm{ng} / \mathrm{ml})$. And MMP-9 levels in AMI patients with DM were found to be significantly more than in MMP-9 levels in patients without DM.

Conclusion: AGEs of DM ( $\uparrow$ Glycated hemoglobin) is associated with increased levels of MMP-9 in AMI patients particularly in poorly controlled DM and appear congruent with the etiopathogenesis of vulnerable plaque. However, large scale studies are needed to ascertain its significance in AMI with DM.
\end{abstract}

Copyright $₫ 2017$ Veenu Rajdan., Ritu Singh and Sanjay Tyagi. This is an open access article distributed under the Creative Commons Attribution License, which permits unrestricted use, distribution, and reproduction in any medium, provided the original work is properly cited.

\section{INTRODUCTION}

Cardiovascular disease is an epidemic in India and having one of the highest burden of CVD and DM worldwide. It has been predicted to be the largest cause of death and disability by 2020 with 4.77 million people dying from coronary artery disease $(\mathrm{CAD})^{[1]}$. Currently throughout the world DM type-2 is the leading cause of cardiovascular diseases. India has one of the largest populations of diabetics in the world with a current estimate of 62 million individuals. ${ }^{[5,6]}$ According to data from clinical studies most diabetics die of cardiovascular disease and atherothrombosis accounts for about 8 of 10 of all diabetic deaths. ${ }^{[1]}$ Acute myocardial infarction (AMI) is a condition when there is evidence of myocardial necrosis in a clinical setting consistent with acute myocardial ischemia. ${ }^{[1]}$ The pathogenesis of AMI involves rupture of an

*Corresponding author: Veenu Rajdan

Department of Biochemistry, Lady Hardinge Medical College, New Delhi, India, G.B.Pant Hospital, New Delhi, India atherosclerotic plaque which has progressed from an initial fatty streak to a complex advanced lesion characterized by deposition of modified LDL, adhesiveness, permeability and thrombogenesis leading to sudden decrease of circulating blood to the myocardium. ${ }^{[2,8]}$ Patients with Diabetes mellitus (DM) have a greater risk of atherosclerotic vascular disease in heart. Diabetes increases the risk of AMI because it increases rate of atherosclerotic progression in DM Type 2 and has been recognized as an independent major cardiovascular risk factor ${ }^{[4]}$ However the etiopathogenesis of this increased rate of Atherosclerotic progression is under research.

Increased intracellular glucose leads to the formation of Advanced glycation end products (AGEs) via Non enzymatic glycation of intra and extracellular proteins. Non enzymatic glycation results from the interaction of glucose with amino groups on proteins. AGEs have been shown to cross-link proteins (e.g., collagen, extracellular matrix proteins) and accelerate atherosclerosis ${ }^{[7,15]}$. Further a family of zincdependent enzymes with proteolytic activity Matrix 
metalloproteinase (MMPs) against connective tissue proteins such as collagen, proteoglycans, and elastin have been implicated in progression of atherothrombogenesis. ${ }^{[9,10]}$

MMP-9 also known as gelatinase B or 92-kDa type IV collagenase is one of the MMPs found to be highly expressed in the vulnerable regions of atherosclerotic plaque and region of foam cell accumulation and may contribute to the remodeling processes associated with atherogenesis and plaque instability thus leading to AMI. ${ }^{[12]}$

Ruptured plaques causing AMI have been shown to have several histomorphological features that are different from stable plaques.Plaques that rupture tend to have a large lipid core, to have inflammatory cell infiltration of the fibrous cap and adventitia to possess a thin cap depleted of smooth muscle cells. Depletion of matrix components from the fibrous cap caused by an imbalance between synthesis and breakdown leads to cap thinning. This predisposes the fibrous cap to rupture, either spontaneously or in response to haemodynamic or other triggers. ${ }^{[18]}$

Rupture of the atherosclerotic plaque and consequent thrombotic occlusion of the artery has been related to local over expression and increased activity of MMPs with enhanced matrix breakdown particularly at the shoulder region of the plaque thus weakening the fibrous cap leading to AMI. ${ }^{[20]}$ We have studied the hypothesis that MMP-9 would infiltrate into circulation and be associated with MI,particularly in the more prone DM Type 2 patients.

\section{METHODS}

Study Population: 30 patients who had symptomatic AMI without DM and 30 patients who had AMI with DM of atleast 10 years duration,within 24 hours of onset and with no history chronic inflammatory disease and cancers (cases) during the study period in Cardiology department, G.B. Pant Hospital and 30 volunteers without DM and 30 volunteers with DM of atleast 10 years duration and no history of AMI, chronic inflammatory disease and cancers during the study period were included in study after informed consent. The study was approved by institutional ethics committte.

$2 \mathrm{ml}$ Venous blood sample was collected from the study population from the antecubital vein with informed consent under sterile conditions.Fresh serum was used to perform routine biochemical investigations and $0.5 \mathrm{ml}$ serum was preserved under $<-20$ degree Celsius for MMP-9 assay.Routine chemistries(Serum Na,Serum K, Serum Urea,Serum Creatinine, Serum Uric acid, Serum Bilirubin, Serum ALT,AST,ALP, Serum Total protein, Serum Albumin, Serum Calcium, Serum Phosphorus, Serum Total cholesterol, Serum Triglycerides, Serum HDL, Serum Amylase, Serum Blood glucose) along with Glycated hemoglobin were carried out in fully automated AU480 analyzer on same day. Plasma MMP-9 levels was estimated using RayBio Human MMP-9 ELISA Kit.

\section{RESULTS}

The observations and results were tabulated the statistical methods used was Student $t$ test, ANOVA as applicable and conclusions were drawn.

MMP-9 levels in patients of AMI without DM was $(22.2 \pm$ $1.2 \mathrm{ng} / \mathrm{ml}$ ) found to be significantly high with $\mathrm{p}<\mathbf{0 . 0 0 1}$ when compared with levels in volunteers without DM $(21.5 \pm 1.2$ $\mathbf{n g} / \mathbf{m l}$ )

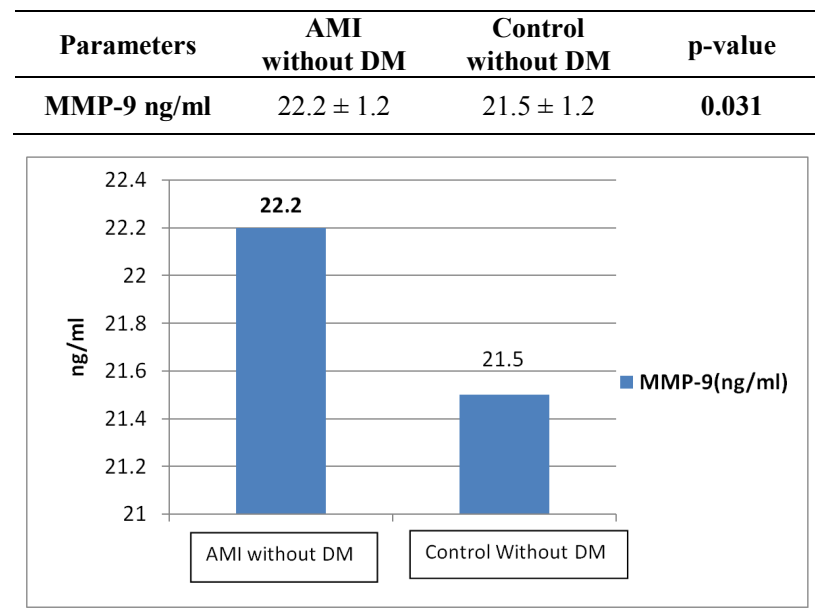

MMP-9 levels in patients of AMI with DM was (24.1 \pm $1.1 \mathrm{ng} / \mathrm{ml}$ ) found to be significantly high with $\mathrm{p}<0.001$ when compared with levels in volunteers with DM (22.4 \pm 1.5 $\mathrm{ng} / \mathrm{ml}$ )

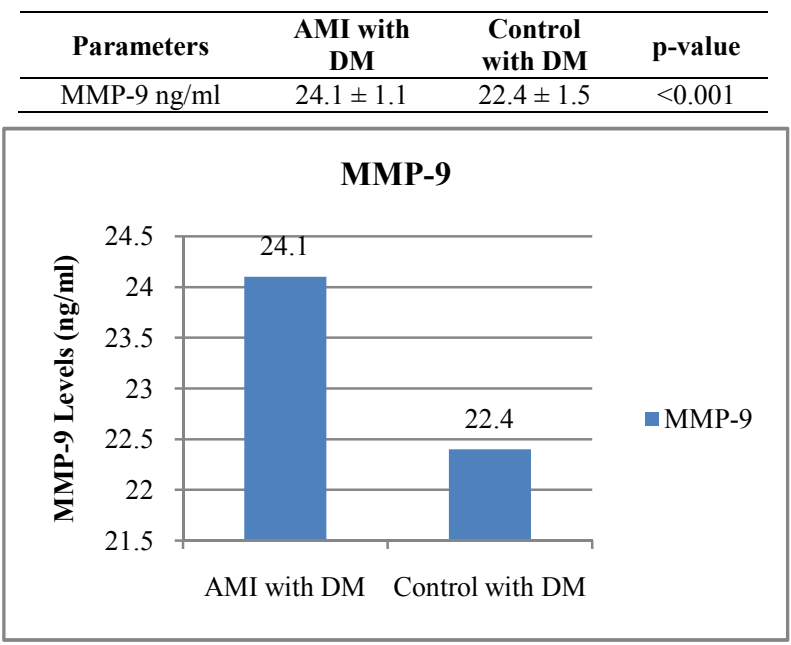

Furthermore MMP-9 levels in patients of AMI with DM was $(24.1 \pm 1.1 \mathrm{ng} / \mathrm{ml})$ found to be significantly high with $\mathrm{p}<0.001$ when compared with levels in patients with AMI without DM $(22.2 \pm 1.2 \mathrm{ng} / \mathrm{ml})$.

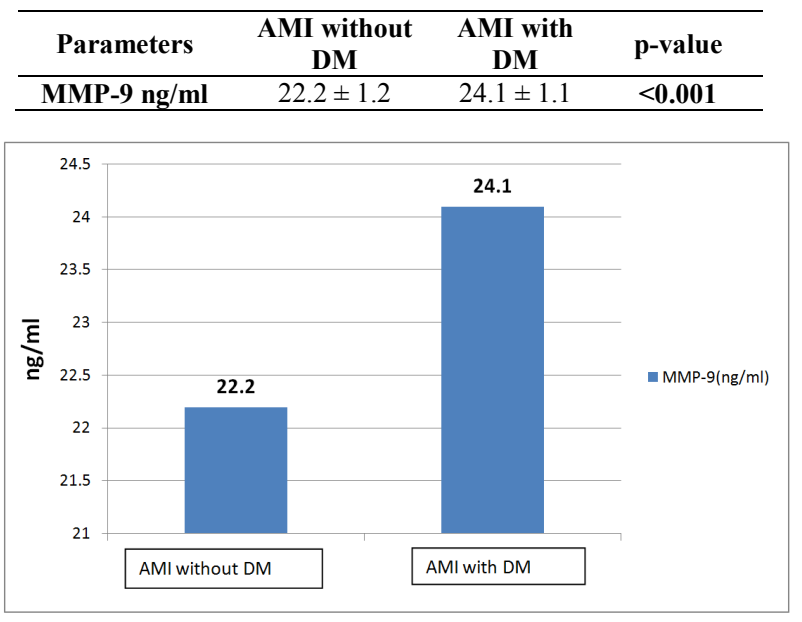

Furthermore patients of AMI had significantly high Glycated Hemoglobin (10.8\%) and Blood glucose (253.7 $\mathrm{mg} / \mathrm{dl})$ 
$\mathbf{p}<\mathbf{0 . 0 0 1}$ than in volunteers with DM $(7.8 \%)$ and $(175.7 \mathrm{mg} / \mathrm{dl})$ respectively.
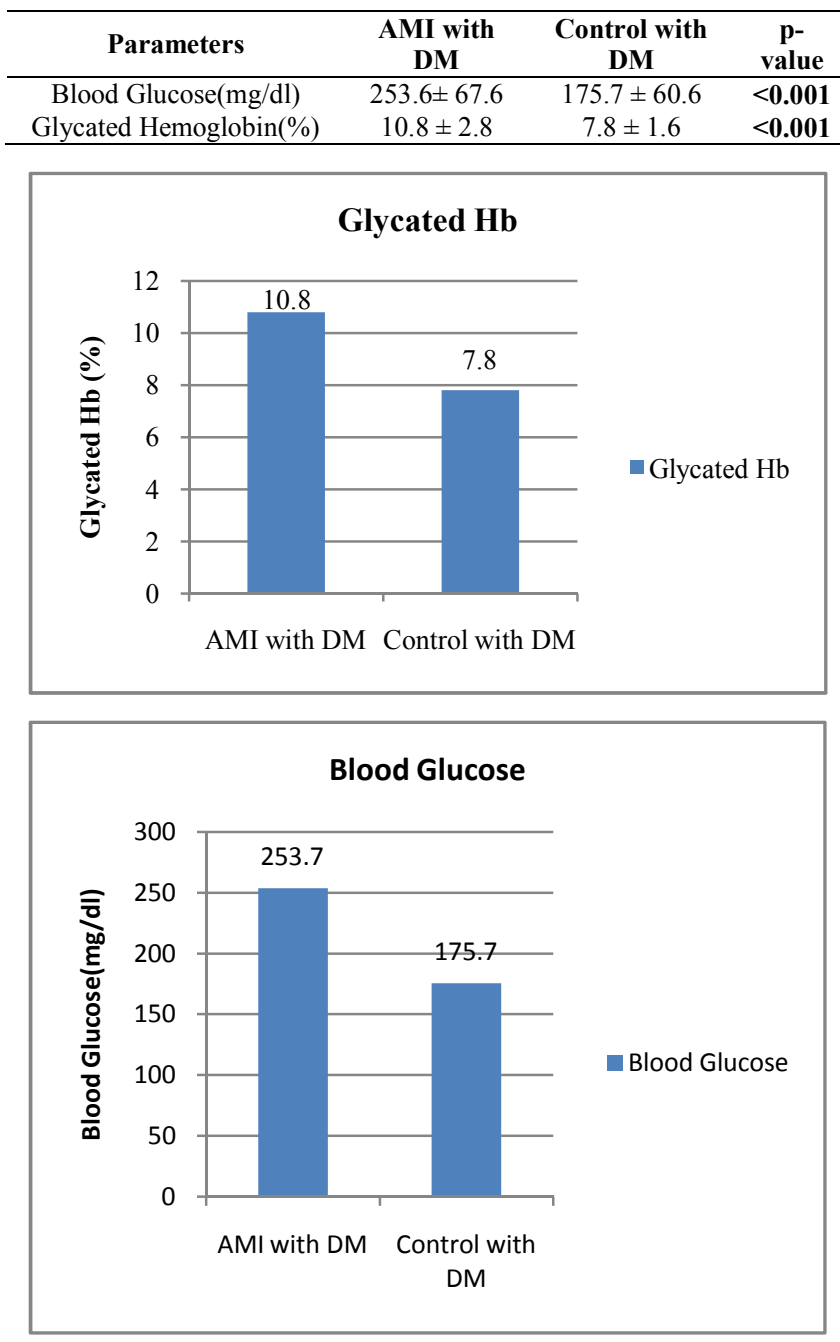

The other test were found as follows:

\begin{tabular}{|c|c|c|c|}
\hline Parameters & AMI with DM & Control with DM & p-value \\
\hline Sodium(meq/L) & $138.2 \pm 4.6$ & $141.6 \pm 4.2$ & 0.004 \\
\hline Potassium(meq/L) & $4.2 \pm 0.6$ & $4.4 \pm 0.3$ & 0.065 \\
\hline Blood Urea(mg/dl) & $41.5 \pm 18.2$ & $26.3 \pm 6.2$ & $<0.001$ \\
\hline $\begin{array}{l}\text { Serum Creatinine } \\
(\mathrm{mg} / \mathrm{dl})\end{array}$ & $1.2 \pm 0.7$ & $0.8 \pm 0.2$ & 0.002 \\
\hline Serum uric acid $(\mathrm{mg} / \mathrm{dl})$ & $4.95 \pm 1.69$ & $4.60 \pm 0.71$ & 0.302 \\
\hline $\begin{array}{c}\text { Serum.Bilirubin } \\
(\mathrm{mg} / \mathrm{dl})\end{array}$ & $0.8 \pm 0.3$ & $0.56 \pm 0.2$ & $<0.001$ \\
\hline ALT(IU/L) & $44.6 \pm 30.7$ & $25.3 \pm 7.3$ & 0.001 \\
\hline AST(IU/L) & $149.6 \pm 152$ & $33.8 \pm 14.4$ & $<0.001$ \\
\hline ALP(IU/L) & $106.2 \pm 29.2$ & $107 \pm 20.8$ & 0.899 \\
\hline Serum Total Protien $(\mathrm{g} / \mathrm{dl})$ & $6.7 \pm 0.4$ & $6.9 \pm 0.3$ & 0.009 \\
\hline $\begin{array}{l}\text { Serum Albumin } \\
(\mathrm{g} / \mathrm{dl})\end{array}$ & $4.0 \pm 0.2$ & $4.2 \pm 0.2$ & 0.001 \\
\hline Calcium(mg/dl) & $9.3 \pm 0.7$ & $9.5 \pm 0.4$ & 0.179 \\
\hline Phosphorus(mg/dl) & $2.9 \pm 0.6$ & $3.5 \pm 0.6$ & $<0.001$ \\
\hline $\begin{array}{l}\text { Total Cholesterol } \\
\text { (mg/dl) }\end{array}$ & $176.9 \pm 48.3$ & $191.8 \pm 35.9$ & 0.181 \\
\hline Triglycerides(mg/dl) & $191.1 \pm 112$ & $205.2 \pm 129.6$ & 0.652 \\
\hline $\begin{array}{l}\text { HDL-Cholesterol } \\
\text { (mg/dl) }\end{array}$ & $38.1 \pm 7.8$ & $40.2 \pm 7.2$ & 0.289 \\
\hline Amylase(U/L) & $52.6 \pm 23.1$ & $69.4 \pm 16.9$ & 0.002 \\
\hline
\end{tabular}

Further we determined coefficient of correlation between MMP-9 levels and Blood glucose levels, glycated Hemoglobin and between blood glucose and glycated hemoglobin found it to be highly significant.

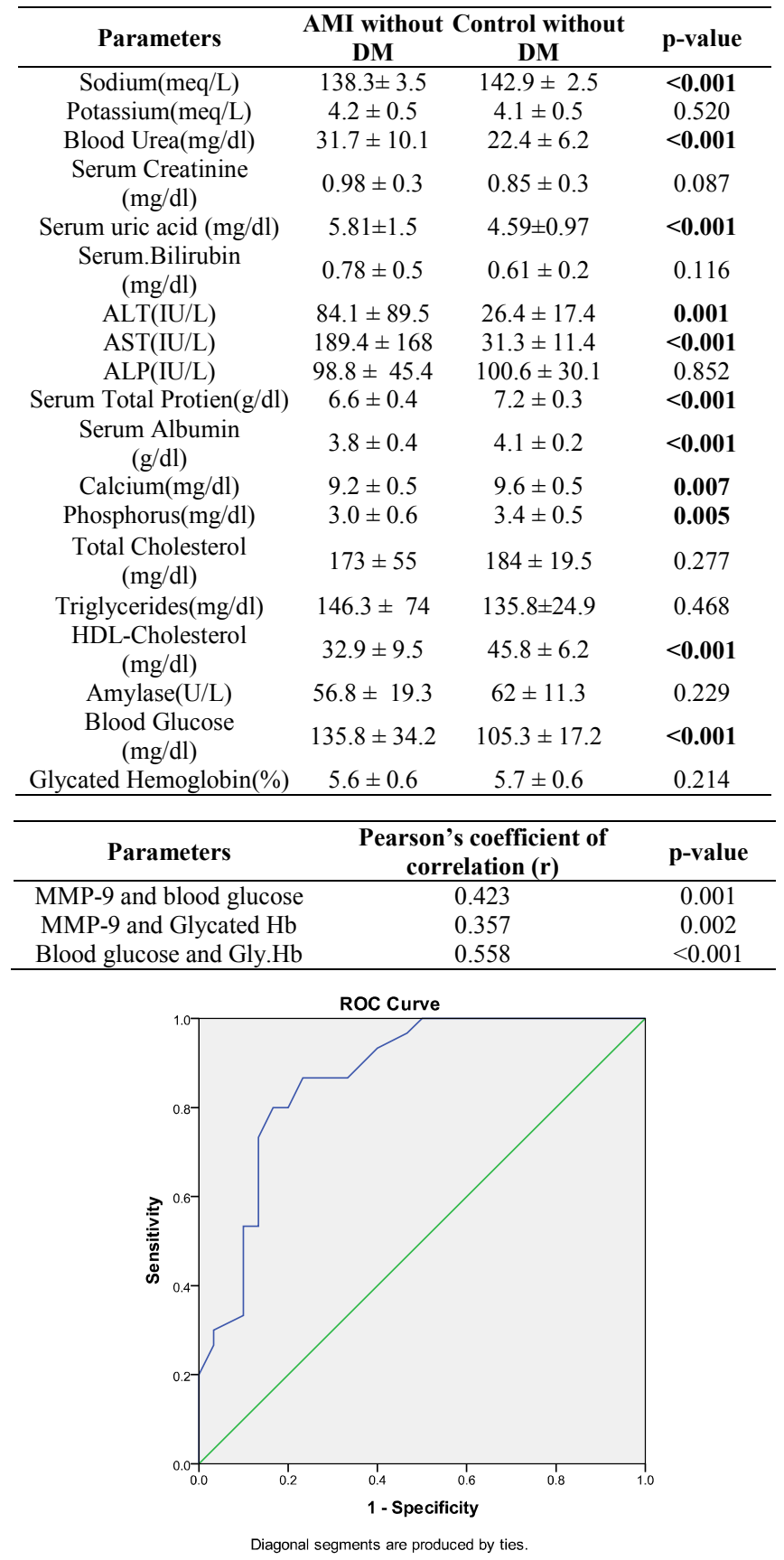

By determining the ROC curve we found the cut off value for MMP-9 by the levels giving highest sensitivity and specificity.

\section{DISCUSSION}

Our study evaluated levels of circulating MMP-9 in AMI without DM and in AMI with DM and in volunteers without DM and in volunters with DM taken as controls.We demonstrated a strong association between poorly controlled DM and MMP-9 levels and increased occurance of AMI.

Our study suggests that MMP-9 in diabetic and non diabetc AMI patients may also constitute as a novel biomarker for characterizing individuals at higher cardiovascular disease risk.

Diabetes and related metabolic diseases such as hyperinsulinemia, insulin resistance and central obesity are 
recognized as major contributors to cardiovascular morbidity and mortality. Recent evidence has shown the significant and independent role of systemic and coronary inflammation in the initiation, progression and precipitation of atherothrombosis superimposed on traditional risk factors. ${ }^{[8,9]}$ Patients with diabetes mellitus have an increased risk of developing extensive arteriosclerosis with its sequelae unstable angina pectoris and acute myocardial infarction.In DM increased intracellular glucose leads to formation of AGEs (Advanced Glycation End Products) via non enzymatic glycation of various intracellular, extracellular proteins and lipids. $^{[8,9,16]}$

DM stimulates a strong immune system response by upregulating specific cytokines, chemokines and leukocyte populations to contribute to increased vascular cell apoptosis and tissue fibrosis during plaque formation. ${ }^{[16]}$ The increase in macrophage numbers associates with reduced collagen content and MMP-9 over expression in human diabetic plaques. ${ }^{[8,9]}$

The activity of MMPs is normally low in healthy tissue but the increased expression and activity of several MMPs in a range of pathological processes, such as inflammation and ventricular remodelling after myocardial infarction, might indicate that they play a role in the pathophysiology and progression of atherosclerotic disease. ${ }^{[16]}$

Few research have suggested that MMP-9 and Advanced Glycated End products can be correlated positively as an atherosclerotic marker and suggested that AGEs induces production of MMP-9 via COX-2's (Cyclo-oxygenase2) and Prostaglandin E-1's increased expression and increased MMP-9 in turn leads to increase chance of plaque instability in patients of AMI. ${ }^{[9]}$

Studies have also shown that atherosclerotic lesions in diabetic patients were more vulnerable as they had larger intimal lesions, more macrophage infiltration and thrombosis compared with those in non diabetic patients. ${ }^{\left[{ }^{9,10]}\right.}$ As acute plaque disruption leads to local thrombin production at the site of vascular injury, this may facilitate proteolytic activation of MMP-9, which may start a vicious circle with platelet aggregation and further generation of thrombin and then more MMP activation. MMP-9 elevation reverses back towards the control range within a week supporting a more active role for MMP-9 in the pathogenesis of plaque instability.

Given that plaque rupture is a key event in triggering cardiovascular events these studies suggest that glycemic control may decrease the mortality and morbidity of cardiovascular disease in diabetic patients by stabilizing atherosclerotic plaques.

\section{CONCLUSION}

In conclusion, plasma MMP-9 concentration was identified as a novel risk marker in patients of AMI. In AMI it was seen that the MMP-9 levels were raised but comparatively less elevation than in AMI patients with DM. Therefore MMP-9 might provide additional information about risk stratification and prognosis will have to be assessed in additional studies with large study population.

\section{Future Recommendations}

Follow up and prognostic studies of MMP-9 and glycated Hemoglobin in patients of AMI with and without DM in a large sample size.

\section{Acknowledgments}

The study was supported by grant from Indian council of medical research (ICMR) New Delhi (ICMR Letter number Letter No-3/2/May2015/PG-ThesisHRD (2) number)

\section{References}

1. Huffman MD, Dorairaj P, Sachdev HS, Osmond C, Fall CHD,Tondon $\mathrm{N}$ et al. Incidence of Cardiovascular Risk Factors in an Indian Urban Cohort. $\mathrm{J} \mathrm{Am}$ Coll Cardiol 2011;57(17):1765-1774

2. Antman EM, Selwyn AP, Loscalzo J.Harrison's Principles of Internal Medicine, 18e. New York: The McGraw-Hill Companies; 2012. Chapter 243, Ischemic Heart Disease; p.1998-2014

3. Houston MC.New Concepts in the Diagnosis and NonSurgical Treatment of Cardiovascular Disease. Intern Med 2014;S11: 002

4. Marx N, Froehlich J, Siam L, Ittner J, Wierse G, Schmidt A et al. Antidiabetic PPAR $\gamma$ Activator Rosiglitazone Reduces MMP-9 Serum Levels in Type 2Diabetic Patients with Coronary Artery Disease. ArterioscolerThromVasc Biol 2003;23:283-288

5. Kaveeshwar SA, Cornwall J. The current state of diabetes mellitus in India. Australas Med $J$. 2014;7(1):45-48

6. Mohan V, Venkatraman JV, Pradeep R. Epidemiology of Cardiovascular Disease in Type 2 Diabetes: The Indian Scenario. J Diabetes Sci Technol 2010;4(1):158170

7. Basta G, Schmidt AM, Caterina RD. Advanced glycation end products and vascular inflammation: implications for accelerated atherosclerosis in diabetes. Cardiovascular Research 2004; 63:582-592

8. Tomkin GH, Owens D. LDL as a Cause of Atherosclerosis. TOATHERTJ2012;5:13-21

9. Halade GV, Jin YF, Lindsey ML. Matrixmetalloproteinase (MMP)-9: A proximal biomarker for cardiac remodeling and a distal biomarker for inflammation. Pharmacol. Ther.2013;139:32-40

10. Blankenberg S, Rupprecht HJ,Poirier O,Bickel C,Smieja M, Hafner G et al. Plasma Concentrations and Genetic Variation of Matrix Metalloproteinase 9 and Prognosis of Patients with Cardiovascular Disease 2003;107:1579-1585

11. Packard RR, Libby P. Inflammation in Atherosclerosis FromVascular Biology to Biomarker Discovery and Risk Prediction. Clin Chem 2008 Jan;54(1):24-38

12. Agewall S. Matrix metalloproteinases and cardiovascular disease. Eur heart J 2006;27:121-122

13. Galis ZS, Johnson C, Godin D, Magid R, ShipleyJM, Ivan E et al. Targeted Disruption of the Matrix Metalloproteinase-9 Gene Impairs Smooth Muscle Cell Migration and Geometrical Arterial Remodeling. Circ Res 2002;91:852-859 
14. Biondi-Zoccai GG, Abbate A, Liuzzo G, Biasucci LM.Atherothrombosis, Inflammation and Diabetes. $J$ Am Coll Cardiol 2003;41(7):1071-7

15. Vlassara H, Palace MR. Diabetes and Advanced Glycation End products. J Intern Med 2002; 251(2):87101

16. Yabluchanskiy A, Ma Y, Iyer RP, Hall ME, Lindsey ML.Matrix Metalloproteinase-9: Many Shades of Function in Cardiovascular Disease. Physiology (Bethesda) 2013 Nov; 28(6): 391-403
17. Liu P, Sun M, Sawsan Sader S. Matrix metalloproteinases in cardiovascular disease. Can $J$ Cardiol 2006 Feb;22(Suppl B):25B-30B

18. Finn AV, Nakano M, Narula J, Kolodgie FD,Virmani R. Concept of vulnerable/unstable plaque. Arterioscler Thromb Vasc Biol. 2010 Jul; 30(7):1282-92.

19. Libby P, Theroux P.Pathophysiology of coronary artery disease. Circulation. 2005 Jun 28;111(25):34818

20. Ravn HB, Falk E. Histopathology of plaque rupture. Cardiol Clin 1999;17:263-270

\section{How to cite this article:}

Veenu Rajdan, Ritu Singh and Sanjay Tyagi (2017) ' Poorly Controlled Diabetes Mellitus Type 2 Is Associated With Increased Mmp-9 Levels And Occurance Of Myocardial Infarction-A Pilot Study', International Journal of Current Advanced Research, 06(05), pp. 3584-3588. 